\title{
Metamodel Development for Predicting Hygrothermal Performance of Wood-Frame Wall under Rain Leakage
}

\begin{abstract}
Lin Wang ${ }^{1}$, Hua Ge ${ }^{2}$ and Liangzhu (Leon) Wang ${ }^{3}$
${ }^{1}$ Postdoctoral Fellow, Department of Building Civil and Environmental Engineering, Concordia University, 1455 de Maisonneuve O., Montreal, QC H3G 1M8, Canada, forestwang2013@gmail.com

${ }^{2}$ Associate Professor, Department of Building Civil and Environmental Engineering, Concordia University, 1455 de Maisonneuve O., Montreal, QC H3G 1M8, Canada, hua.ge@concordia.ca

${ }^{3}$ Associate Professor, Department of Building Civil and Environmental Engineering, Concordia University, 1455 de Maisonneuve O., Montreal, QC H3G 1M8, Canada, leon.wang@concordia.ca

Abstract. In recent years, stochastic modeling has been increasingly applied to investigate the uncertainties of input parameters in hygrothermal simulation and the moisture damage risks of building envelopes. Generally, stochastic modeling requires hundreds or even thousands of simulations to take into account the uncertainties of input parameters, which is computationally intensive and timeconsuming. This paper aims to apply polynomial and neural network metamodel as a substitute for the traditional hygrothermal model, to predict the hygrothermal performance of building envelopes. In the previous study carried out by the authors, stochastic simulations have been performed based on the traditional hygrothermal model, to investigate the hygrothermal performance of wood-frame walls under different rain leakage levels. The material properties and rain deposition factors were considered as stochastic variables, and stochastic simulations were performed under three rain leakage scenarios: $1 \%, 0.5 \%$ and $0.1 \%$ of wind-driven rain. In this paper, the stochastic inputs (the hygric material properties and rain deposition factor) and outputs (the maximum moisture content and mold growth index over a 5-year period of the simulation) of a conventional $2 \times 6$ wood-frame wall are used to develop the metamodels through polynomial regression and neural network methods. The metamodels are developed for each rain leakage scenario, and the stochastic data of the three rain leakage scenarios are aggregated together to train another metamodel. It is found that the metamodels generally perform well to predict the maximum moisture content and mold growth index. The metamodels for low rain leakage scenarios are better than those for high rain leakage scenarios and the neural network metamodel is more accurate than polynomial metamodel for high rain leakage scenarios, i.e. $1 \%$ of rain leakage.
\end{abstract}

Keywords: Neural Network Metamodel, Polynomial Metamodel, Hygrothermal Simulation, Woodframe Wall, Rain Leakage.

\section{Introduction}

In recent years, the stochastic modeling approach has been increasingly applied to investigate the uncertainties of input parameters in hygrothermal simulation and the moisture damage risks of building envelopes. Generally, stochastic modeling requires hundreds or even thousands of simulations to take into account the uncertainties of input parameters, which is computationally intensive and time-consuming. To improve computational efficiency, a statistical meta-model can be developed as a substitute for the traditional hygrothermal model, to predict the hygrothermal performance of building envelopes. 
There are several comparative studies to investigate the performance of different metamodeling methods (Van Gelder et al., 2014; Janssen et al., 2015; Ostergard et al., 2018). And the hygrothermal performance of the building envelopes have been approximated by various metamodel methods, such as generalized additive model, polynomial regression and neural network (Zewdu Taffese and Sistonen, 2016; Zanetti Freire et al., 2017; Marincioni et al., 2018; Ostergard et al., 2018; Tijskens et al., 2019). According to the comparison study by ANNEX 55, the best metamodeling techniques are polynomial regression (PR), multivariate adaptive regression splines (MARS), and sigmoidal transfer function neural networks, and it was suggested that the metamodel can only be used within the range of the training data values. (Janssen et al., 2015). On the contrary, the data set in different ranges may need different metamodels to ensure their reliability. Most of the previous studies have focused on the performance of different types of metamodels, however, there is a lack of studies investigating the reliability of the metamodels at different data ranges.

According to the stochastic analysis performed by Wang and Ge (2019), the rain leakage level significantly influences the moisture performance of building envelopes. This paper develops metamodels for predicting moisture performance of a conventional 2x6 wood-framed wall under different rain leakage scenarios. The polynomial regression and sigmoidal transfer function neural network methods are employed to develop the metamodels. Metamodels are developed for three rain leakage scenarios: $0.1 \%, 0.5 \%$ and $1 \%$ of wind-driven rain. Additionally, a metamodel representing all the three scenarios is developed by training the aggregated stochastic datc

Maximum Absolute metamodels.

\section{Methods}
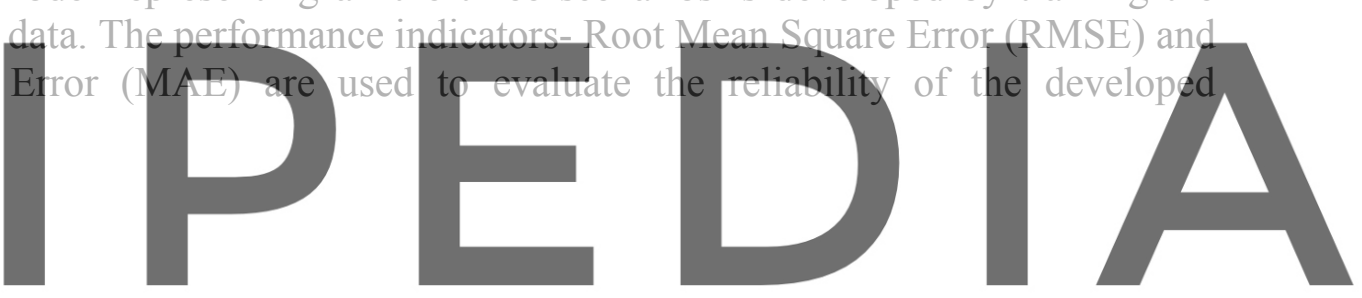

\subsection{Hygrothermall Model}

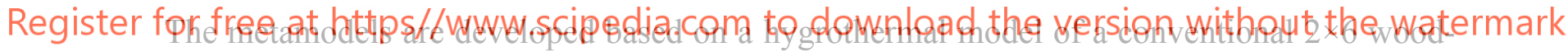
framed wall. Figure 1 shows the configuration of the investigated wall, and Table 1 shows the mean values of the material properties of each component in the wall.

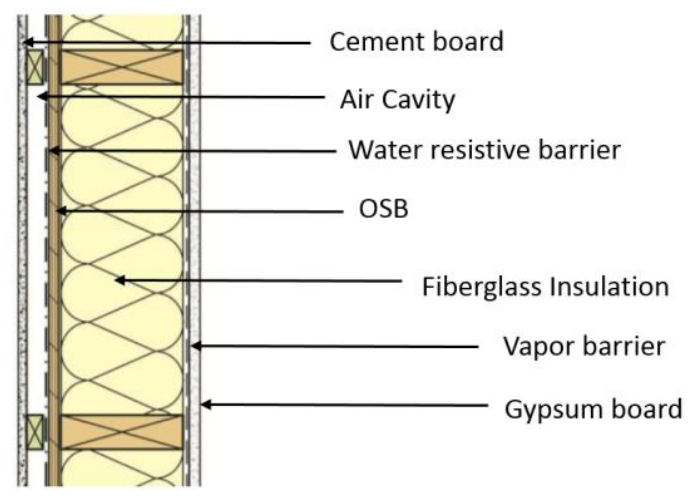

Figure 1. Configuration of $2 \times 6$ wood framed wall. 
Table 1. Material properties.

\begin{tabular}{llllllll}
\hline & $\begin{array}{l}\rho \\
\left(\mathrm{kg} / \mathrm{m}^{3}\right)\end{array}$ & $\theta_{\text {por }}\left(\mathrm{m}^{3} / \mathrm{m}^{3}\right)$ & $\mathrm{W}_{\mathrm{f}}\left(\mathrm{kg} / \mathrm{m}^{3}\right)$ & $\begin{array}{l}\mu_{\text {Dry }} \\
-\end{array}$ & $\begin{array}{l}\mathrm{D}_{\mathrm{ww}} \\
\left(\mathrm{m}^{2} / \mathrm{s}\right)\end{array}$ & $\begin{array}{l}\mathrm{c} \\
(\mathrm{J} / \mathrm{kg} \cdot \mathrm{K})\end{array}$ & $\begin{array}{l}\lambda \\
(\mathrm{W} / \mathrm{m} \cdot \mathrm{K})\end{array}$ \\
\hline Cement Board & 1130 & 0.479 & 152 & 905 & $2.16 \mathrm{E}-8$ & 840 & 0.24 \\
\hline Air Gap & 1.3 & 0.999 & - & 0.56 & - & 1000 & 0.13 \\
\hline $\begin{array}{l}\text { Water Resistive } \\
\text { Barrier }\end{array}$ & 400 & 0.001 & 0.9 & 328 & - & 1500 & 2.4 \\
\hline OSB & 650 & 0.9 & 377 & 994 & $1.29 \mathrm{E}-10$ & 1880 & 0.1 \\
\hline Fiberglass & 30 & 0.99 & 208 & 1.35 & - & 840 & 0.036 \\
\hline Vapor barrier & 130 & 0.001 & - & $4 \mathrm{E} 6$ & - & 2300 & 2.3 \\
\hline Gypsum Board & 625 & 0.706 & 430.625 & 172 & $3.47 \mathrm{E}-11$ & 870 & 0.16 \\
\hline
\end{tabular}

$\rho$ - bulk density; $\theta_{\text {por- }}$ porosity; $W_{f}-$ saturation water content; $\mu_{D r y}-$ vapor resistance factor at dry state; $\mathrm{D}_{\mathrm{ww}^{-}}$moisture diffusivity at saturation wáter content; $\mathrm{c}$ - specific heat capacity; $\lambda$ termal conductivity

The boundary conditions are listed in Table 2. and the Canadian Weather Year for Energy Calculation (CWEC) data of Vancouver is used as weather data except for the rain data, which are extracted from the WUFI weather database. The wind-driven rain is calculated based on the semi-empirical model in ASHRAE 160 (2016). The equation of the semi-empirical model is

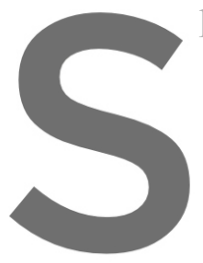
presented as follows:
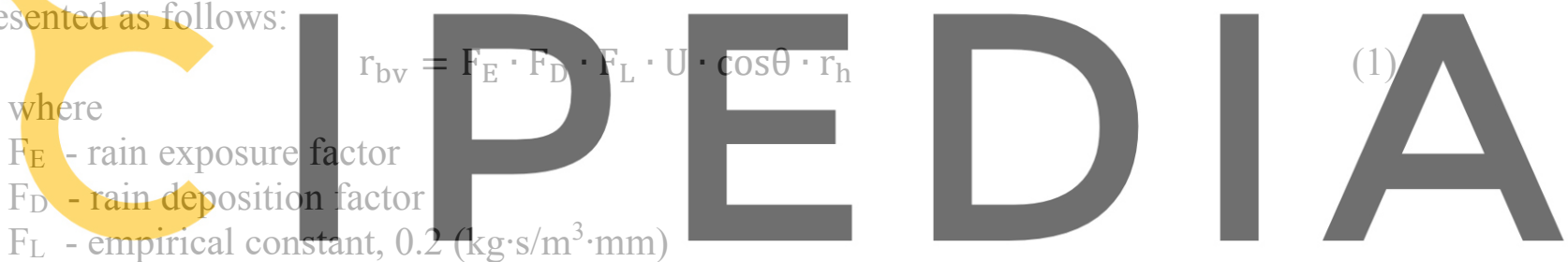

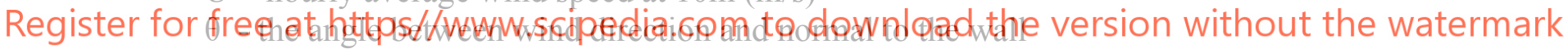
$\mathrm{r}_{\mathrm{h}}$ - rainfall intensity, horizontal surface $(\mathrm{mm} / \mathrm{h})$

Table 2. Boundary conditions.

\begin{tabular}{llllllll}
\hline $\begin{array}{l}\alpha_{\text {in }} \\
\left(\mathrm{W} / \mathrm{m}^{2} \cdot \mathrm{K}\right)\end{array}$ & $\begin{array}{l}\alpha_{\text {ex }} \\
\left(\mathrm{W} / \mathrm{m}^{2} \cdot \mathrm{K}\right)\end{array}$ & $\begin{array}{l}\beta_{\text {in }} \\
(\mathrm{s} / \mathrm{m})\end{array}$ & $\begin{array}{l}\beta_{\text {ex }} \\
(\mathrm{s} / \mathrm{m})\end{array}$ & $\begin{array}{l}\alpha_{\mathrm{s}} \\
-\end{array}$ & $\begin{array}{l}\alpha_{1} \\
-\end{array}$ & $\begin{array}{l}\mathrm{F}_{\mathrm{E}} \\
-\end{array}$ & $\begin{array}{l}\mathrm{F}_{\mathrm{D}} \\
-\end{array}$ \\
\hline 8 & 17 & $5.6 \mathrm{E}-8$ & $1.19 \mathrm{E}-7$ & 0.6 & 0.9 & 1.0 & 0.35 \\
\hline
\end{tabular}

To investigate the impact of rain leakage on the hygrothermal performance of the wall assembly, hygrothermal models are created for three rain leakage scenarios: $0.1 \%, 0.5 \%$, and 1 $\%$ of wind-driven rain. The wall is assumed to face east orientation, which receives the highest amount of wind-driven rain. The penetrated rain wáter is assumed to be deposited on the exterior surface of OSB. The moisture content and mold growth index at the interior surface of OSB are used for performance evaluation. The details of the model setup can be found in Wang and $\mathrm{Ge}(2019)$. 


\subsection{Data Preparation}

To evaluate the moisture problem and mold growth risks, stochastic simulations were performed for 5 years starting from Oct. 2012 based on DELPHIN and MATLAB (Wang and Ge, 2019). The stochastic input and output data are used for training the metamodels.

The input data includes stochastic hygric material properties of OSB and fiberglass and the rain deposition factor. The material properties are assumed to follow the normal distribution, the mean values and standard deviations are determined from literature (Kumaran et al., 2003; Mukhopadhyaya et al., 2007). The rain deposition factor is assumed to follow uniform distribution from 0.35 to 1.0 as prescribed in ASHRAE 160 (2016). The stochastic inputs are sampled by the Latin Hypercube Sampling technique, and the stochastic models are generated for the three rain leakage scenarios. For each scenario, 100 stochastic models are generated. In total, simulations are performed for 300 stochastic models. Table 3 shows the mean values and standard deviations of the stochastic inputs. Other parameters of the hygrothermal model are kept as deterministic values. The output data used for training the metamodel is the stochastic results of maximum moisture content and mold growth index for the 5-years' simulation.
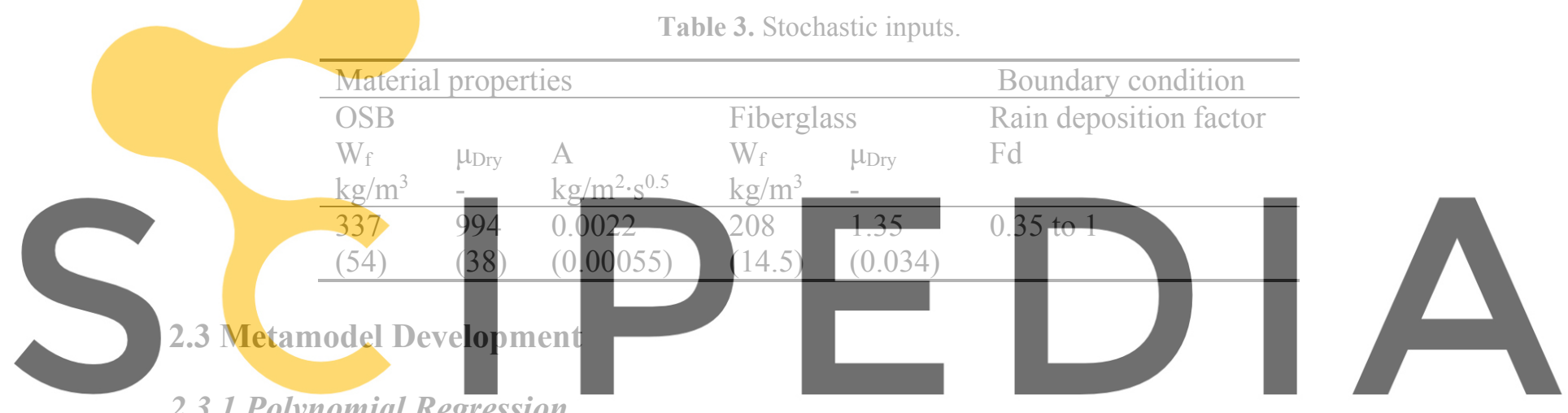

\subsubsection{Polynomial Regression}

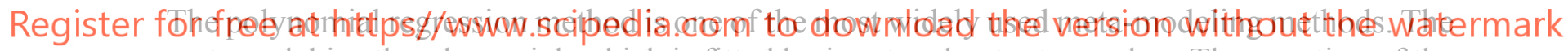
metamodel is nth polynomial, which is fitted by input and output samples. The equation of the metamodel can be written as follows (Jin et al., 2001):

where

$$
\hat{y}=b_{0}+\sum_{n=1}^{m} \sum_{i=1}^{p} b_{n i} x_{i}^{n}+\sum_{n=1}^{m} \sum_{k=1}^{m} \sum_{i=1}^{p} \sum_{j=1}^{p} b_{n k i j} x_{i}^{n} x_{j}^{k}
$$

$\hat{y}$ - estimated output

$\mathrm{x}$ - input vectors

p- the number of inputs

$\mathrm{m}$ - the order of the polynomial

b- regression coefficients

In general, the regression coefficients can be determined based on the least square method. The accuracy of polynomial regression metamodel is influenced by sample size and order number. According to ANNEX 55 (Janssen et al., 2015), a third-order polynomial performs the best for approximating an original model with 14 parameters, while a second-order model significantly reduces the number of coefficients with only slightly worse performance than the third-order model. The Root Mean Square Error (RMSE), which measures the accuracy of the metamodel, has no significant reduction after the sample size is higher than 100. Therefore, in 
this paper, the sample size is 100 for each rain leakage scenario, and the metamodel is developed based on the second-order polynomial. For the metamodel representing all the three rain leakage scenarios, there are 300 samples. The polynomial metamodels are developed using the Polyfitn toolbox in MATLAB (D'Errico, 2012).

\subsubsection{Neural Network Metamodel}

A neural network is composed of an input layer, an output layer, and one or more hidden layers in between. Figure 2 shows a typical architecture of the neural network. These layers are interconnected so that the information can be transferred from one layer to another through transfer function. At each hidden layer, there are several neurons that contain the transfer function. The number of neurons in the hidden layer is defined by the users and the transfer function can be radial basis function or sigmoidal transfer function. According to Van Gelder et al. (2014), the radial basis function network needs more training samples to obtain the same accuracy with a sigmoidal transfer function network. And the performance of one hidden layer neural network with 9 neurons could be better than that of two hidden layers with 17 and 19 neurons at each layer when predicting the number of hours with room temperature higher than $25{ }^{\circ} \mathrm{C}$ in a semi-detached dwelling model. Therefore, in this paper, the sigmoidal transfer function network is used to develop the metamodel, and there is only one hidden layer with 10 neurons. The number of neurons in the input layer and the output layer is equal to the number of input and output parameters. In this paper, there are six input parameters (the six stochastic

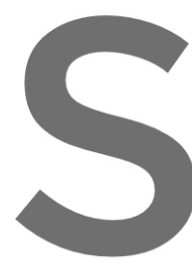
variables shown in $\mathrm{T}$ or mold growth index which shows a better neural network metanio
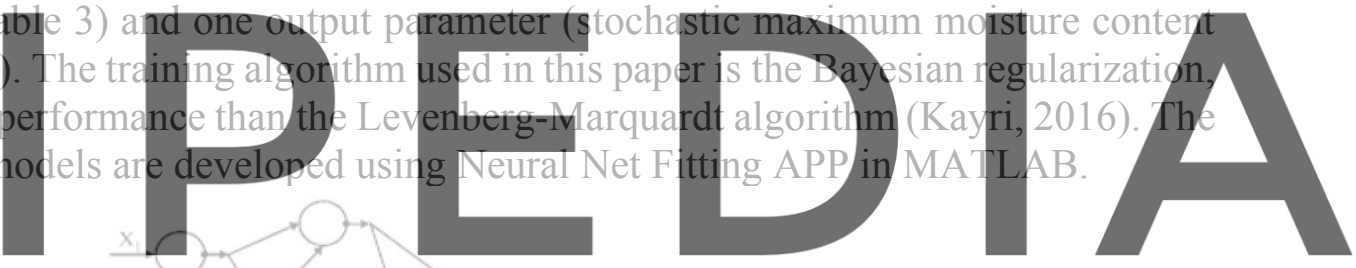

Register for free at https//www.scipedia.com-to download the version without the watermark

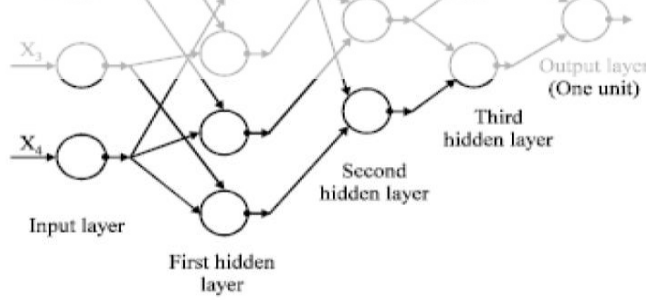

Figure 2. A typical neural network model (Galkin and Lawell, 2013).

\section{Results and Discussion}

\subsection{Metamodels for Moisture Content}

Figure 3 shows the comparison of maximum moisture content between metamodels and the originals model for the test data that are not participated in training the metamodels. In this paper, $85 \%$ of the sample data set are used for training, and $15 \%$ are used for testing. And Table 4 shows the RMSE and MAE of the two types of a metamodel for each scenario. It can be seen 
from Figure 3 that the metamodels for $0.1 \%$ rain leakage scenario have the best performance.

All the metamodel outputs are almost on the 45-degree line, and the trendline of the outputs from metamodel is almost overlapping with the 45-degree line for both polynomial and neural

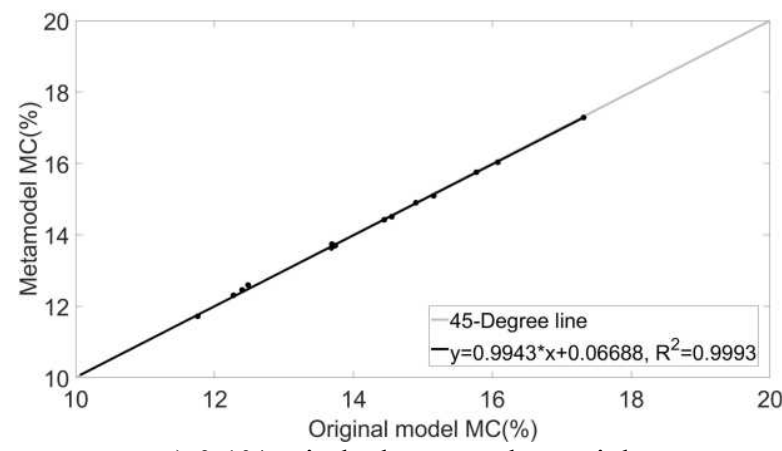

a) $0.1 \%$ rain leakage_polynomial

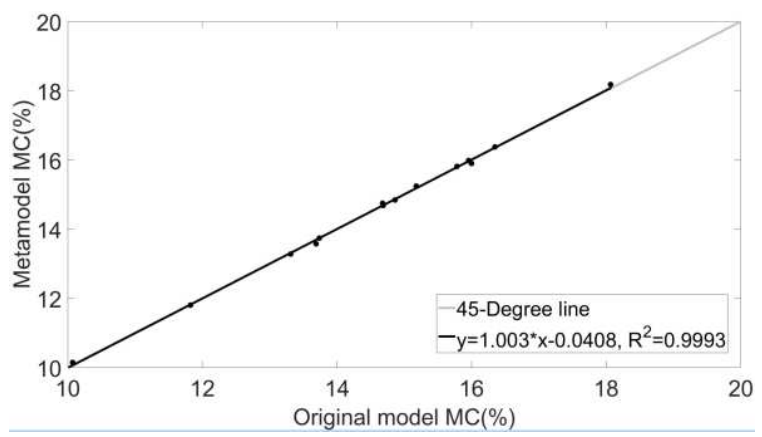

b) $0.1 \%$ rain leakage_neural network

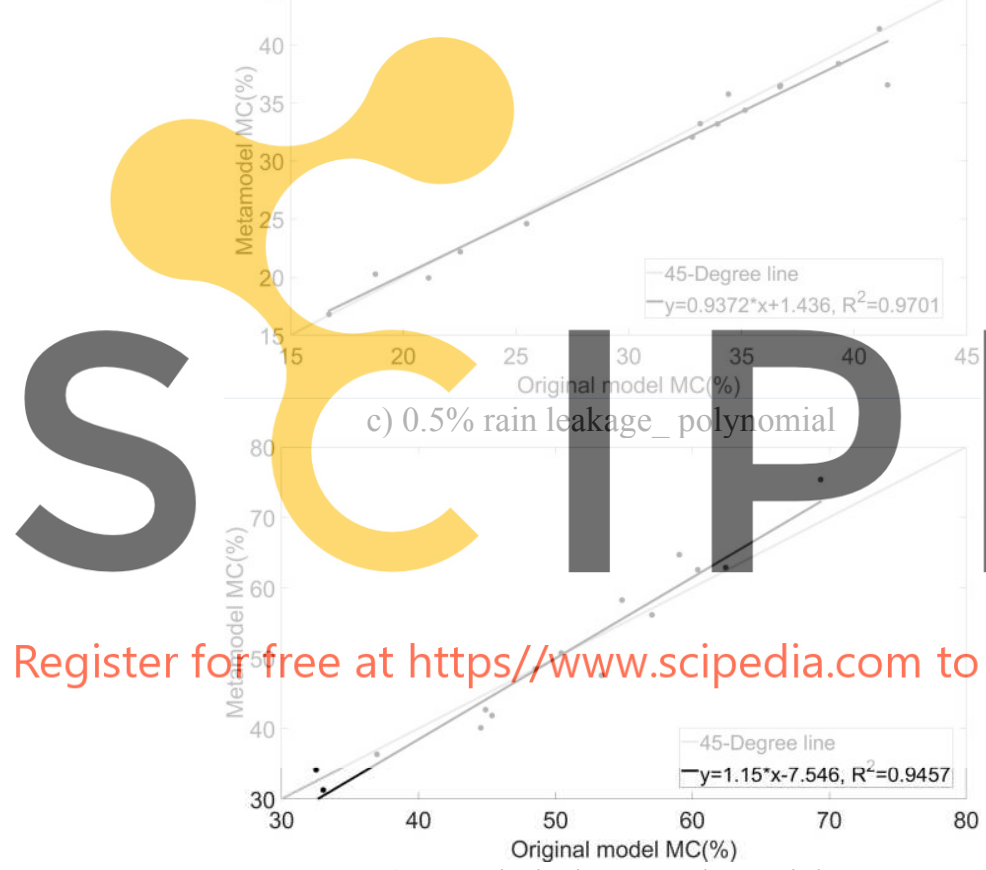

e) $1 \%$ rain leakage_polynomial

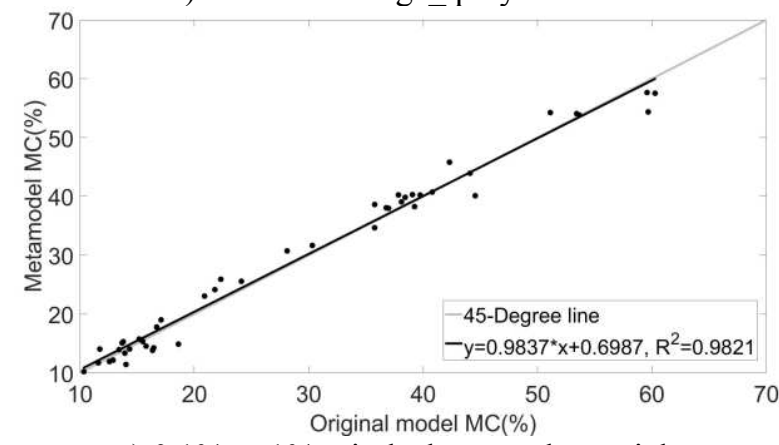

g) $0.1 \%$ to $1 \%$ rain leakage_polynomial
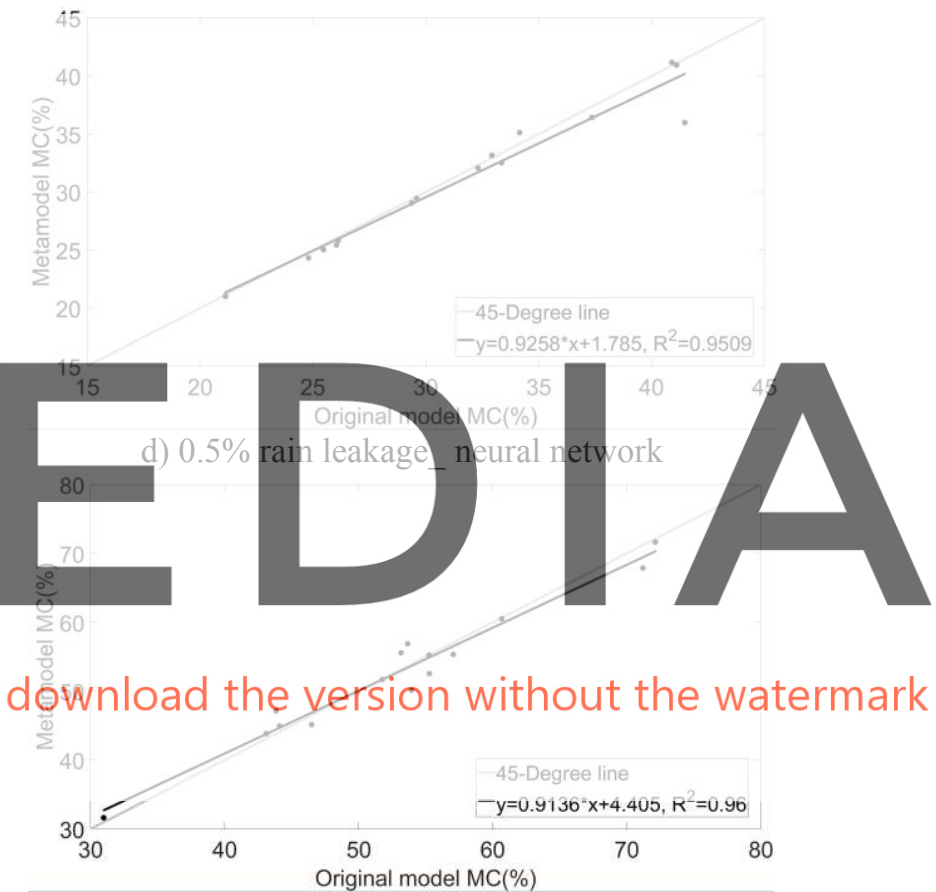

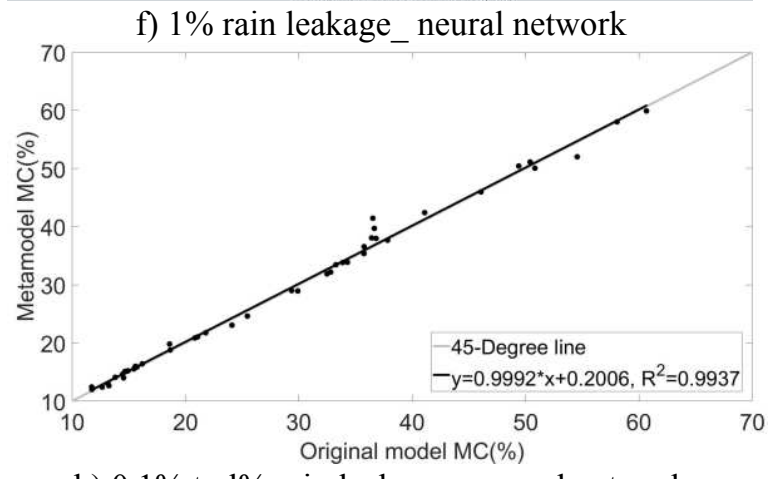

h) $0.1 \%$ to $1 \%$ rain leakage _ neural network

Figure 3. Comparison of the outputs (maximum moisture content) between original models and metamodels for different rain leakage scenarios. 
Table 4. Comparison of the metamodel performance between polynomial regression and neural network methods for different rain leakage scenarios (maximum moisture content).

\begin{tabular}{lllllllll}
\hline & \multicolumn{1}{l}{ Polynomial } & \multicolumn{7}{c}{ Neural network } \\
\hline & $0.1 \%$ & $0.5 \%$ & $1 \%$ & $\begin{array}{l}0.1 \% \\
\text { to } 1 \%\end{array}$ & $0.1 \%$ & $0.5 \%$ & $1 \%$ & $\begin{array}{l}0.1 \% \\
\text { to } 1 \%\end{array}$ \\
\hline RMSE & 0.05 & 1.49 & 3.29 & 2.05 & 0.06 & 1.50 & 2.11 & 1.12 \\
\hline MAE & 0.11 & 4.93 & 5.99 & 5.31 & 0.12 & 5.49 & 3.80 & 4.91 \\
\hline
\end{tabular}

network methods. Therefore, the predicted values from the metamodels are almost equal to those from original models and the metamodels perform very well for predicting the maximum moisture content. For the $0.5 \%$ and $1 \%$ rain leakage scenarios, the outputs from metamodels are distributed around the 45-degree lines, and the trendlines deviate from the 45-degree lines.

The outputs of $1 \%$ rain leakage scenario is more spreading than those of $0.5 \%$ rain leakage scenario, which means the accuracy of the $1 \%$ rain leakage metamodels is lower than that of $0.5 \%$ rain leakage metamodels. Figure $3 \mathrm{~g}$ and $\mathrm{h}$ show the metamodels representing the whole range of rain leakage from $0.1 \%$ to $1 \%$. It can be observed the outputs of the neural network metamodel are closer to the 45-degree line than those of the polynomial metamodel, which means the neural network metamodel has a better performance than polynomial metamodel.

The performance of these metamodels can be verified by observing their RMSE and MAE as presented in Table 4 . It can be seen that the $0.1 \%$ rain leakage scenario has the lowest RMSE and MAE, it is followed by $0.5 \%$ and $1 \%$ scenarios. The metamodels representing all the rain leakage scenarios have but lower than the $1 \%$ MAE of neural network While, for the $1 \%$ rain scenarios, the neural network
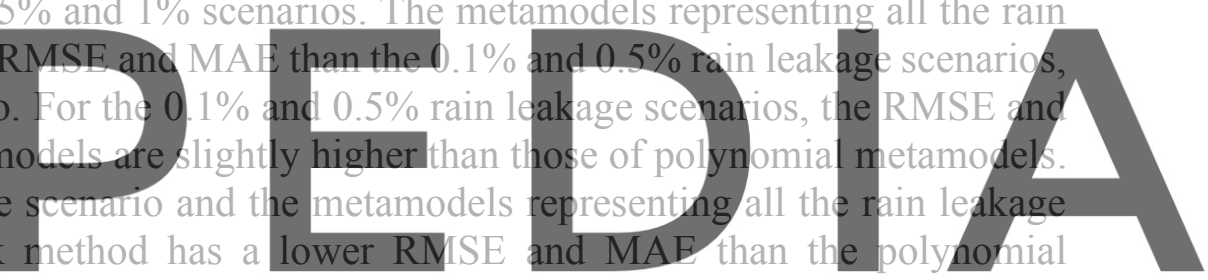
regression method.

Register for free at https//www.scipedia.com to download the version without the watermark

Table 5. Comparison of the metamodel performance between polynomial method and neural network method for different rain leakage scenarios (maximum mold growth index).

\begin{tabular}{lllllllll}
\hline & \multicolumn{2}{l}{ Polynomial } & \multicolumn{7}{c}{ Neural network } \\
\hline & $0.1 \%$ & $0.5 \%$ & $1 \%$ & $\begin{array}{l}0.1 \% \\
\text { to } 1 \%\end{array}$ & $0.1 \%$ & $0.5 \%$ & $1 \%$ & $\begin{array}{l}0.1 \% \\
\text { to } 1 \%\end{array}$ \\
\hline RMSE & 0.10 & 0.14 & 0.15 & 0.39 & 0.07 & 0.16 & 0.09 & 0.12 \\
\hline MAE & 0.23 & 0.39 & 0.24 & 1.01 & 0.12 & 0.36 & 0.20 & 0.37 \\
\hline
\end{tabular}

Table 5 shows the performance of the metamodels for predicting the maximum mold growth index. The conclusions that can be drawn from this table are similar to those for the maximum moisture content. The scenarios with higher rain leakage have higher RMSE and MAE, and the neural network method has lower RMSE and MAE than the polynomial method, particularly at higher rain leakage levels.

\section{Conclusions}

This paper developed polynomial and neural network metamodels to simulate the maximum 
moisture content and mold growth index of a conventional $2 \times 6$ stud wall under different rain leakage levels. The main conclusions of this paper are: 1) In general, the developed metamodels are performing well to substitute the original hygrothermal models. 2) The metamodels for lower rain leakage levels (from $0.1 \%$ to $0.5 \%$ rain leakage) perform better than those with higher rain leakage levels (from $0.5 \%$ to $1 \%$ rain leakage). 3) Neural network metamodel performs better than polynomial metamodel, especially for the scenarios with higher rain leakage level.

\section{OCID}

Lin Wang: https://orcid.org/0000-0002-6529-1123

Hua Ge: http://orcid.org/0000-0003-1368-4301

Liangzhu (Leon) Wang: https://orcid.org/0000-0002-3656-7020

\section{References}

ASHRAE. (2016). ANSI/ASHRAE Standard 160-2016 Criteria for moisture-control design analysis in buildings. Atlanta, GA: American Society of Heating Refrigerating and Air Conditioning Engineers Inc.

D'Errico, J. (2012). Matlab function 'polyfitn',

http://www.mathworks.com/matlabcentral/fileexchange/34765-polyfitn, last accessed on Oct. 20, 2019

Galkin, I. and Lowell, U.M. (2013). Polynomial neural networks.

http://ulcar.uml.edu/ iag/CS/Polynomial-NN.html, last accessed on Oct. 20, 2019.

Janssen, H., Roels, S., Gelder, L. V. and Das, P. (2013). Final report of IEA Annex 55- Subtask 2: Probabilistic tools. Gothenburg, Sweden: International Energy Agency.

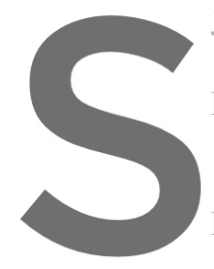

Jin, R. Chen, W and Sinpson, T. W. (2001) Comparative stucie modelling criteria. Struct

Kayri, M. (2016). Predictive neural networks: a conparative 21(2), 20

Kumaran, M.K., Lackey, J hygrothermal properties of several wood-based buth Building Physics Conference, Leuven, Belgium.

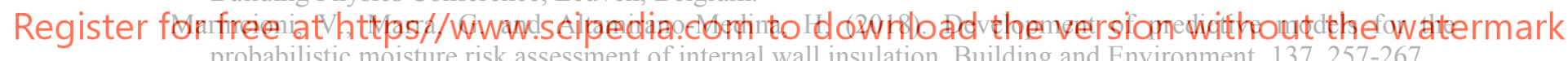
probabilistic moisture risk assessment of internal wall insulation. Building and Environment. 137, 257-267.

Mukhopadhyaya, P., Kumaran, M.K., Lackey, J.C., van Reenen, D. and Tariku, F. (2007). Hygrothermal properties of exterior claddings, sheathing boards, membranes and insulation materials for building envelope design, NRCC-50287. National Research Council of Canada, Ottawa, Canada.

Ostergard, T., Lund Jensen, R. and Enersen Maagaard, S. (2018). A comparison of six metamodeling techniques applied to building performance simulations.Applied Energy. 211, 89-103.

Tijskens, A., Roels, S. and Janssen, H. (2019). Neural networks for metamodelling the hygrothermal behaviour of building components. Building and Environment. 162, 106282.

Van Gelder, L., Das, P., Janssen, H. and Roels, S. (2014). Comparative study of metamodelling techniques in building energy simulation: guidelines for practitioners. Simulation Modelling Practice and Theory, 49, 245 257.

Wang, L. and Ge, H. (2019). Effect of rain leakage on hygrothermal performance of highly insulated wood-framed walls: a stochastic approach. Canadian Journal of Civil Engineering. Special Issue: Durability and Climate Change.

Zanetti Freire, R., dos Santos, G.H. and dos Santos Coelho, L. (2017). Hygrothermal dynamic and mould growth risk predictions for concrete tiles by using least squares support vector machines.Energies. 10(8), 1903.

Zewdu Taffese, W. and Sistonen, E. (2016). Neural network based hygrothermal prediction for deterioration risk analysis of surface-protected concrete facade element. Construction and Building Materials. 113, 34-48. 